\title{
Commentary on The Persecuting God and the Crucified Self: The Case of Olav and the Transformation of His Pathological Self-Image
}

\section{Dissolution of "The Committee": Mentalization and Psychic Transformation in the Case Of Olav}

\author{
MAX S. MALITZKY ${ }^{\text {a,b }}$ \\ ${ }^{a}$ Graduate School of Applied and Professional Psychology, Rutgers University \\ $\mathrm{b}$ Correspondence concerning this article should be addressed to Max Malitzky, Graduate School of Applied and \\ Professional Psychology, Rutgers University, 152 Frelinghuysen Road, Piscataway, NJ 08854 \\ Email: max.malitzky@gmail.com
}

\begin{abstract}
Stålsett, Engedal, and Austad's (2010) case study of Olav demonstrates how a treatment integrating the insights and techniques from a wide variety of traditions helped resolve the symptoms in a man with treatment resistant, psychotic depression and a host of underlying personality problems. This commentary focuses on highlighting the change in Olav's ability to mentalize and consequently to begin to transform his deeply held representations of self and object.
\end{abstract}

Key words: mentalization; "transformation" in therapy; psychoanalysis; case formulation

\section{INTRODUCTION}

Stålsett et al. (2010) case study is subtitled, "The Case of Olav and the Transformation of His Pathological Self-Image," indicating their serious ambitions. They highlight for us that the fundamental issue in this case is that of "transformation" in psychotherapy on the level of self and object representation, and in so doing situate themselves within the psychoanalytic tradition (Wallerstein, 1995). In a landmark paper, Freedman (1985) articulates that transformation of primitive mental contents into more organized and differentiated psychic structures capable of creating higher levels of symbolization represents "the hard rock, the central issue which we deem essential for the understanding of human nature" (317). In this view, how a patient is helped to undergo transformation is the central question in psychotherapy research, and all successful publications in the field must first demonstrate transformation and then explain what they believe to be its underlying mechanism. The authors of "The Case of Olav" are successful on both accounts. The purpose of this discussion, therefore, is to bring the strengths and accomplishments of this very evocative and convincing case study into high relief.

As a psychoanalytically oriented clinician with an interest in experimentally validated, psychoanalytic approaches, to wend my way through this complex text I would like to use the concept of "mentalization," which Stålsett et al. describe as "the ability to understand the mental 
state of oneself and others based on overt behavior, and thus to see oneself from the outside, and others from the inside" (p. 54). In fact I will make the argument that the promotion of mentalization in the VITA program was the essential element in Olav's cure, because a lack in Olav's capacity to mentalize was the factor underlying Olav's psychological distress. Issues of faith provided the medium for transformation of self and object representation and the growth of mentalization. At the end of his treatment, Olav had begun to develop a positive self-concept as well as a benevolent superego, as could be seen in his disentanglement from "The Committee" he had psychically created and his decision to align himself, internally, with a loving God.

\section{MENTALIZATION AND PSYCHOPATHOLOGY}

Stålsett et al.'s usage of the term "mentalization" comes from Bateman and Fonagy (2004), who write that "mentalizing simply implies a focus on mental states in oneself or in others, particularly in explanations of behavior" (p. 1). This simple definition belies the complex mental processes that make this stance possible, as well as the fact that its exercise is a developmental capacity that cannot be taken for granted in all individuals. When used upon oneself, mentalization requires two seemingly paradoxical actions. First, affects must be experienced rather than repressed, disavowed, or dissociated. This allows for the recognition and naming of emotions. At the same time, individuals must also have the capacity to recognize their affects as mental products rather than concrete events. The distinction here involves experiencing oneself as the author of one's experience rather than the passive recipient of intruding, inexplicable states of mind. With this comes the individual's ability to stand apart from and observe emotions. It is this capacity, for example, that that is recruited in third wave behaviorism (Hayes, 2004) and mindfulness meditation (Linehan, 1993). When interacting with others, mentalization is what underlies empathy, fluid social interaction, and, ultimately, the experience of intersubjectivity.

Perhaps even more important in the case of Olav is the connection between mentalization and symbolization. Fonagy and Bateman (2004) describe symbolization as "a fluency in mental state language" that replaces two developmentally earlier modes of thinking and experiencing, by combining them (p. 7). These two are "the psychic equivalence mode," in which both inner and outer reality are treated as identical, and the "pretend mode," in which inner and outer reality are entirely disassociated. When mentalization fails to function, the individual can become stuck in the psychic-equivalence mode, in which inner reality takes on all the trappings of real experience, destroying the capacity for "meta-cognition"-i.e., thinking about thinking - and for entertaining others' perspectives. Alternatively, in the pretend mode, the individual may seem to mentalize, but in truth there is a lack of engagement with the reality of the outside world. 
Fonagy, Gergely, Jurist, \& Target, M. (2002) ${ }^{1}$ present empirical studies showing that insecure or disorganized attachment is strongly associated with low levels of mentalization. In insecure attachment, insufficient mirroring and attunement on the part of the parent leads to the child's inability to represent his own experience and to the feeling that parts of self-experience are concrete, alien, or non-symbolized. In cases where there is physical or emotional maltreatment of the young child, mentalization is even more strongly compromised. If the child perceives himself as the recipient of too much of the adult's aggression, the child may overattend to the dangers of the external world rather than feeling safe to experience the contents of his mind. In contrast or simultaneously, the child may deny the reality of the other's malevolent intentions. Instead, he may defensively erect a set of rigid, self-other representations to preserve a modicum of security. This phenomenon, originally put forth by Kernberg, and redescribed more recently by Clarkin, Yeomans, and Kernberg (2006), has been described under the heading of "splitting.” Here, too the psychic equivalence and pretend modes may predominate.

\section{CASE FORMULATION AND ASSESSMENT}

Having introduced the fundamentals of mentalization, I will now turn to review Stålsett et al.'s (2010) formulation of Olav's case from the vantage point of this concept. According to the authors, Olav was

heavily burdened with guilt and shame and had great difficulty in tolerating and regulating his feelings, which frequently resulted in regressive dissociations and panic attacks. He could not stand being alone and he repeatedly became involved in short clinging relationships, often ending in sudden break-ups with suicidal despair (2010, p. 58).

Underlying this state of interpersonal and affective dysregulation was a primitive set of representations of self and other, in which Olav, seeing himself as a crucified martyr, was tortured and condemned by a Committee of heavenly voices "forbidding him to have his own feelings and thoughts" (p. 58). His primary goal in treatment was to "attain the freedom 'to be Olav' ... and [to be] loved by a merciful God, without the burden of his father's perfectionist ideals or aspirations”(p. 58).

An account of Olav's life clearly reveals a history of poor attachment and cumulative, emotional trauma bordering on parental abuse. The loss of his twin brother at 18 months of age was followed by what Olav described as a maternal depression. One might theorize that this interfered with Olav's capacity to form an internal working model associated with secure attachment, which in turn contributed to a basic deficit in mentalization and affect regulation. Added to this was his account of his parents' veneration of his deceased brother and his father's excessively demanding standards, which Olav internalized as masochistic solution for achieving

\footnotetext{
${ }^{1}$ This volume, Affect Regulation, Mentalization and the Development of the Self, is perhaps the foundational text in the field of mentalization. In no way do I feel that I have done justice to the complexity of the theory in my short introduction, and I direct the reader to this work if more is desired.
} 
love and validation. Between his father's moral imperatives and his sense of his mother as fragile and ineffective, Olav appears to have had no choice but to dissociate from negative affects and autonomous strivings. This is evoked by Olav's mother's characterization of the outside world and "worldly games" as dangerous.

Thus, from the point of view of mentalization, we can hypothesize that an environmental failure led Olav to a defensive retreat from reflective functioning. Having learned that his feelings and desires were unacceptable, his ability to experience them and then stand apart from and reflect on them was turned off. Instead, a psychic-equivalence mode predominated in which thoughts were equated with actions and then needed to be dissociated. This was revealed in particular by the affect consciousness interview, during which Olav showed strength in being able to name his affects but an absolute unwillingness to experience them. This in turn led to a sense of self that oscillated between different "self-states," in which he saw himself as either "crucified," unreal, disconnected, or ineffectual. Coinciding with this was a rigid set of split selfobject representations, in which Olav was either debased, immoral, unworthy, or hateful. Olav's mother was held in mind as a loving presence who had gone missing forever, and his father, as a moralistic persecutor who was always present. Finally, consistent with Olav's borderline organization was the hyperactivation of his attachment system; his use of primitive defenses like projection and dissociation; his impaired reality testing; and his urgent but ambivalent object relations (McWilliams, 1994).

A question arises here about the authors' choice of assessment methods. Although the authors chose to formulate the case of Olav largely in psychodynamic, object-relations language, they relied primarily on the SCID-I and SCID-II to create "DSM" diagnoses (APA, 1994), and on the BDI, SCL-90, and IIP as outcome measures. At the current time, a number of empirically validated, semi-structured interviews exist to assess personality organization, such as the Adult Attachment Interview (Steele \& Steele, 2008), which has many clinical and research applications. Using these assessments might have allowed the authors to provide a complementary psychoanalytic diagnosis (Alliance of Psychoanalytic Organizations, 2006) as well as baseline and post-treatment scores that could be used to measure structural change.

\section{TREATMENT STRATEGIES AND COMPONENTS}

Nearly all of treatment strategies and components in the VITA model can be understood with mentalization in mind. Perhaps one of the most important components of the treatment is the psychoeducational uses of the initial Affect Consciousness Interview, and the series of psychoeducational lectures introducing the patient to therapy, which described a theory of affects and explained the nature of separation issues. Given the time-limited nature of the VITA program and the difficulty that Olav had standing apart from his experience, it seems essential that he had a cognitive scaffolding that he could use to make sense of and contextualize his deeply emotional and potentially confusing experiences.

The focus on mentalization, especially reflective functioning, continues in the weekly existential and narrative groups. According to the authors, the existential group facilitated a 
broad perspective... of the self and therapy process...This kind of weekly practice develops the art of "meta-reflection," creating distance from the patient's emotional turmoil and enhancing his or her coping and insight (p. 54).

Further, by writing key life stories in the narrative group patients develop the capacity of perspective taking. "This strategy also contributes to the development of meta-reflection” (p. 54). These two activities in the existential and narrative groups prove absolutely essential in challenging the psychic equivalence mode of functioning, in which affects and their related cognitions cannot be experienced at a distance and take precedence over all other pieces of cognitive input. Meditation and relaxation groups further promote the ability to detach enough from cognitions and affects, so that they can be simultaneously experienced and reflected upon.

Three additional activities - individual therapy, group therapy and art therapy — are in place to stretch these nascent mentalizing capacities are far as they could go, as well as to provide patients with space to create or receive affectively powerful insight about the historical and unconscious roots of their emotions and behavior. In particular, the talk therapies are transference-focused, helping patients learn to find the "right address" rather than using old transference paradigms to distort experience in the here and now. Art therapy was perhaps the most impressive modality of treatment in Olav's case, as it opened space for a profound emotional engagement with unconsciously held self and object representations. Further, by allowing Olav space to create a powerfully charged scene and then use it to talk about his experience, the capacity for symbolization was nurtured; and also transitional space, by definition a mentalization mode (Winnicott, 1971), was constructed.

\section{THE COURSE OF TREATMENT}

Perhaps the finest part of the case of Olav is the authors' detailed description of Olav's clinical transformation from a state of non-mentalization and rigidly held, maladaptive self-other representations, to a state of greater symbolization and reflection marked by a growing flexibility, nuance, and maturity in object relations. The authors have described the central theme of the first phase of treatment (Weeks 1-4) as "Daring to Join with Others” (p. 61). Olav's "difficulties in trust, envy, lack of confidence, and feeling condemned” were brought into relief during an aggressive confrontation with another patient (p. 63). In psychodynamic group therapy, he came to the realization that "he needed to use his anger more constructively to build a border around himself and felt relieved that he could feel angry without condemning himself”(p. 63). Here, one can clearly see that Olav's interpersonal functioning was being interfered with by his tendency to dissociate his anger, rather to mentalize about it. It seems that he came to see the links among his condemnation from The Committee; the denying and projecting of his mental contents; and his feeling penetrated, unbounded, and merged with a hostile environment. (Note that these are all a clear illustration of paranoid dynamics [Bion, 1959, 1970; McWilliams, 1994]). Despite some degree of insight into the defensive meaning of his dissociation and desymbolization, Olav continued to "[practice] a strict censorship, fearing loss of control if he expressed his feelings. He said he often went to bed to avoid feelings”(p. 65).

Perhaps this state of consciousness can be most evocatively discovered in Olav's drawing from the first weeks of art therapy. In the first week, he drew The Committee as 
A big, black engulfing eye holding me caught like a backwash. The black is not rage, but unavoidable sadness. I have an inner tribunal of judges who keep me and condemn me. I feel suppressed and squeezed but also secure (Figure 1, p. 92).

When asked to draw himself, he turned in an empty page and said he had "no resources" (p. 63). A figure of his family showed little human representation and symbolized an impending catastrophe. Here, we see that Olav's representation of self and other was comprised of an empty (evacuated) or crucified (damaged) self related to a consuming and undifferentiated other that also served as a symbol of the psychic void that had been created within himself, through the use of dissociation. Yet Olav showed himself to be preconsciously aware of the fact that this primitive, sado-masochistic object relationship was meant to ward of annihilatory experiences, as represented in his drawing of his family's ship headed for a catastrophic collision with an iceberg.

In the second phase of treatment (weeks 5-8), Olav began to represent his "Inner Wolf” in conflict with The Committee. This marked Olav's emergent willingness to experience his angry feelings, rather than projecting them into the internal object of the angry Committee. In art therapy, Olav's presentation of God began to change as well. He said, about his drawing of himself,

Beneath is a concrete wall hiding flames and passion. I want to dare to be happy, to let go. But the feelings are locked up beneath the reinforce concrete. Above I have drawn bombing raids from enemy lines, I am occupied land (p. 67).

Here we see a move from the black orb of psychic obliteration to a state of intrapsychic conflict.

However, some paranoid themes predominate. About his representation of his father, he said, "Deep inside is suppressed desire and passion” and that "he has God in his pocket”(p. 67). Two things are exemplified here. First, we see that Olav had become able to mentalize and consider the complex states of mind in others. Rather than blacking out his mental capacities so as to avoid the mental life of others, he had become more able to tolerate empathy and emotional knowing. In the drawing we can see fully articulated human figures, with some concrete carving up of the body to symbolize psychic conflict. We can see Olav as caught in a dialectical state where concreteness and mentalization are battling for prominence. Also, God is a transitional object available for object use instead of projective-introjective object relating (Winnicott, 1970).

Not unsurprisingly, this transformation from God as a rigid, psychic placeholder to a vividly alive and resonant internal object provoked a spiritual crisis in Olav. Up until this point, Olav had used God as a way to avoid his subjectivity and to disempower himself. Now, having realized God as a transitional representation of his existential fears and longings, he entered a state of mourning for the self that he had compromised through a long history of masochistic, self-destructive behavior.

During the final phase of treatment, Olav showed himself to be much more capable of mentalizing his anger "without falling apart in shame and guilt, which was a strong positive 
indicator for his future” (p. 71). Further, Olav realized that he no longer needed to fall back on The Committee in order to dissociate from his feelings of anger. He said, with great insight, "Now I have responsibility. The voices of The Committee are my own lack of mercy to me"(36). In art therapy Olav began to resolve his splitting and expressed his ambivalence. He no longer treated his mother as an all-good object, and was able to express his anger over her psychological and actual abandonment of him. He showed that he was willing to empathize with his father's own psychological pain without having to let go of his angry feelings. During this phase of treatment, relapse prevention was employed through discussion of termination. Borderline patients have a particular vulnerability around the issue of separation, as it tends to hyperactivate their attachment hunger to the extent that it compromises their ability to self-reflect and mentalize (Bateman \& Fonagy, 2004)

\section{CONCLUSION: MENTALIZATION AND THERAPEUTIC ACTION}

In summarizing the change mechanisms in Olav's case, Stålsett et al. (2010) state:

[We] believe the work with existential concerns is the greatest strength of the guiding concept, and one of the most important contributors to Olav's improvement. The transformation of the God image and the harsh Committee from abusive to affirming was the crucial therapeutic work. ... The emergence of an affirming God representation seemed to contribute to his growing ability to live alone and renounce his regressive, clinging relational patterns (p. 78).

This strikes me as fundamentally accurate but in need of expansion. Based on my analysis above, I propose that it is truer to the narrative facts of Olav's case to conclude that work with existential/religious concerns within the framework enhanced mentalization was the mechanism underlying therapeutic effectiveness in his case. By daring to engage with Olav's psychic reality as it was represented in his religious symbolization (e.g., as represented by the regular pictures that he drew during the VITA program)_rather than dismissing this psychic reality as symptomatic or insane-allowed Olav to feel safe, respected, and even loved. In this context, Olav's ability to mentalize flourished, and he began to let go of his defensive withdrawal from the world of intersubjective relating and his perniciously rigid, self-other representations. In the final analysis, Olav had transformed the bad, internal object of the harsh Committee into a positive, internal representation. What is perhaps most incredible was VITA's ability to jump-start this process, which can take many individuals a lifetime to complete, and which, for an even greater number of individuals, never occurs.

\section{REFERENCES}

Alliance of Psychoanalytic Organizations (2006). Psychodynamic diagnostic manual: (PDM). Silver Spring MD: Psychodynamic Diagnostic Manual Publishing.

APA 1994). Diagnostic and statistical manual of mental disorders, 4th ed. Washington, D.C.: American Psychiatric Association.

Bateman, A. \& Fonagy, P. (2004). Psychotherapy for Borderline Personality Disorder: Mentalization based treatment. Oxford, UK: Oxford University Press. 
Bion, W.R. (1959). Attacks on linking. The International Journal of Psychoanalysis, 40, 308315.

Bion, W.R. (1973 [2004]). Attention and interpretation. Lanham, MD: Jason Aronson.

Clarkin, J.F., Yeomans, F.E., \& Kernberg, O.F. (2006). Psychotherapy for Borderline Personality: Focusing on object relations. Arlington, VA: American Psychiatric Publishing, Inc.

Fonagy, P., Gergely, G., Jurist, E.L., \& Target, M. (2002). Affect regulation, mentalization and the development of the self. New York, NY: Other Press.

Freedman, N. (1985). The concept of transformation in psychoanalysis. Psychoanalytic Psychology, 2, 317-339.

Hayes, S. C. (2004). Acceptance and commitment therapy, relational frame theory, and the third wave of behavior therapy. Behavior Therapy, 35, 639-665.

McWilliams, N. (1994). Psychoanalytic diagnosis: Understanding personality structure in the clinical process. New York, NY: The Guildford Press.

Linehan, M. (1993). Cognitive-behavioral treatment of Borderline Personality Disorder. New York, NY: The Guilford Press.

Stålsett, G., Engedal, L.G., \& Austad, A. (2010). The persecuting God and the crucified self: The case of Olav and the transformation of his pathological self-image. Pragmatic Case Studies in Psychotherapy, Vol. 6(2), Article 1, 49-100: Available: http://hdl.rutgers.edu/1782.1/pcsp_journal

Steele, H. \& Steele, M. (2008) Clinical applications of the adult attachment interview. New York, NY: The Guilford Press.

Wallerstein, R.S. (1995). The talking cures. New Haven, CT: Yale University Press.

Winnicott, D.W (1971 [2005]). Playing and reality. New York: Routledge. 